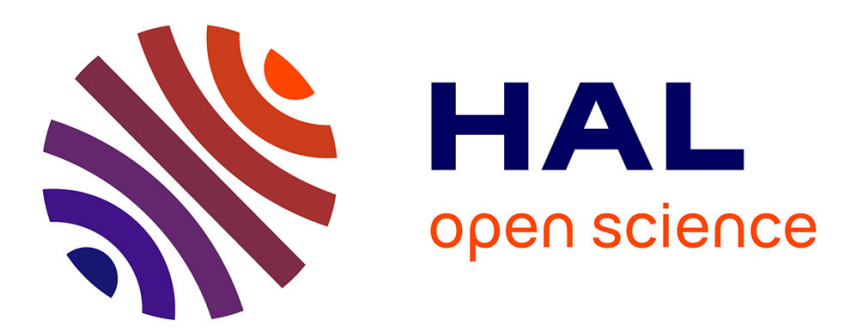

\title{
Linear and nonlinear optical properties of co-sputtered Ge-Sb-Se amorphous thin films
}

Tomáš Halenkovič, Jan Gutwirth, Tintu Kuriakose, Marek Bouška, Mathieu

Chauvet, Gilles Renversez, Petr Němec, Virginie Nazabal

\section{- To cite this version:}

Tomáš Halenkovič, Jan Gutwirth, Tintu Kuriakose, Marek Bouška, Mathieu Chauvet, et al.. Linear and nonlinear optical properties of co-sputtered Ge-Sb-Se amorphous thin films. Optics Letters, 2020, 45 (6), pp.1523-1526. 10.1364/OL.386775 . hal-03100338

\section{HAL Id: hal-03100338 \\ https://hal.science/hal-03100338}

Submitted on 6 Jan 2021

HAL is a multi-disciplinary open access archive for the deposit and dissemination of scientific research documents, whether they are published or not. The documents may come from teaching and research institutions in France or abroad, or from public or private research centers.
L'archive ouverte pluridisciplinaire HAL, est destinée au dépôt et à la diffusion de documents scientifiques de niveau recherche, publiés ou non, émanant des établissements d'enseignement et de recherche français ou étrangers, des laboratoires publics ou privés. 


\title{
Linear and nonlinear optical properties of co-sputtered Ge-Sb-Se amorphous thin films
}

\author{
TOMÁŠ HALENKOVIČ, ${ }^{1}$ JAN GUTWIRTH, ${ }^{1}$ TINTU KURIAKOSE, ${ }^{2}$ MAREK \\ BOUŠKA, ${ }^{1}$ MATHIEU CHAUVET, ${ }^{2}$ GILLES RENVERSEZ, ${ }^{3}$ PETR NĚMEC, ${ }^{1}$ \\ AND VIRGINIE NAZABAL, ${ }^{4,1}$ * \\ ${ }^{1}$ Department of Graphic Arts and Photophysics, Faculty of Chemical Technology, University of Pardubice, 53210 Pardubice, Czech Republic \\ ${ }^{2}$ Department of Optics, FEMTO-ST Institute, UMR CNRS 6174, Université Bourgogne Franche-Comté, 25030 Besançon, France \\ ${ }^{3}$ Aix Marseille Univ, CNRS, Centrale Marseille, Institut Fresnel, Marseille, France \\ ${ }^{4}$ Univ Rennes, CNRS, ISCR (Institut des Sciences Chimiques de Rennes) - UMR 6226, F-35000 Rennes, France \\ *Corresponding author: virginie.nazabal@univ-rennes1.fr
}

Received XX Month XXXX; revised XX Month, XXXX; accepted XX Month XXXX; posted XX Month XXXX (Doc. ID XXXXX); published XX Month XXXX

\begin{abstract}
Amorphous thin films co-sputtered from $\mathrm{GeSe}_{4}$ and $\mathrm{Sb}_{2} \mathrm{Se}_{3}$ targets were investigated for potential applications in the field of nonlinear optics. Depending on the sputtered film composition, linear optical properties were studied by ellipsometry. Kerr coefficient and two-photon absorption coefficient were estimated using Sheik-Bahae's formalism for co-sputtered films of $\mathrm{GeSe}_{4}-\mathrm{Sb}_{2} \mathrm{Se}_{3}$ compared to $\mathrm{GeSe}_{2}-\mathrm{Sb}_{2} \mathrm{Se}_{3}$ pseudo-binary system and $\mathrm{As}_{2} \mathrm{Se}_{3}$ as reference. Kerr coefficient was found within the range of $4.9-21 \times 10^{-18} \mathrm{~m}^{2} \mathrm{~W}^{-1}$. Quantitatively by means of figure of merit at $1.55 \mu \mathrm{m}$, thin films with compositions of $\mathrm{Ge}_{7} \mathrm{Sb}_{25} \mathrm{Se}_{68}$ and $\mathrm{Ge}_{9} \mathrm{Sb}_{20} \mathrm{Se}_{71}$ having estimated Kerr coefficient of about $10.1 \times 10^{-18} \mathrm{~m}^{2} \mathrm{~W}^{-1}$ and $13.4 \times 10^{-18} \mathrm{~m}^{2} \mathrm{~W}^{-1}$ should be considered for the future nonlinear optical integrated platforms. Such compositions being close to $\left(\mathrm{GeSe}_{4}\right)_{50}\left(\mathrm{Sb}_{2} \mathrm{Se}_{3}\right)_{50}$ pseudo-binary (i.e. Ge $\left.{ }_{7.5} \mathrm{Sb}_{25.0} \mathrm{Se}_{67.5}\right)$ provides just the trade-off between high Kerr coefficient and low optical losses related to two-photon absorption.
\end{abstract}

http://dx.doi.org/10.1364/OL.99.099999

Chalcogenide glasses and amorphous thin films possess a variety of properties, which make them attractive in the field of phase-change memories, (bio)chemical sensors, solar cells, NWIR, MWIR and LWIR photonics etc. These are the low phonon energies responsible for wide transmission window in the infrared spectral range enabling rare-earth ions emissions in MWIR and LWIR, photoconductivity, photosensitivity and high optical nonlinearities. The later include an ultrafast all-optical signal processing while having the third-order nonlinearities between 2 to 3 orders of magnitude greater than silica $\left(n_{2}=3.2 \times 10^{-20} \mathrm{~m}^{2} \mathrm{~W}^{-1}\right)$ [1]. High optical nonlinearities in these materials make them suitable for waveguides and heterostructure-based nonlinear optical devices [2-5]. Nonlinear (NL) effects in silicon waveguides at the telecommunication wavelength (i.e. $1.55 \mu \mathrm{m}$ ) have been studied extensively so far. However, NL losses in silicon due to the absorption by free carriers generated via two photon absorption (2PA) limit conversion efficiencies. For their part, possible limitation of amorphous chalcogenides may come with relatively low optical bandgap energies, often correlated with high multiphoton absorption [6], such as 2PA, which may exceed $\sim 0.3$ $\mathrm{cm} \cdot \mathrm{GW}^{-1}$ at telecom wavelength depending on composition $[4,7]$. Another disadvantage of chalcogenides may lie in their photosensitivity, which has so far not been taken into account in the figure of merit, in order to predictively select the really most suitable compositions before getting on the manufacture of nonlinear optics (NLO) integrated platforms. Given the growing interest in integrated optics for NLO applications, the study of amorphous chalcogenides thin film allows us to evaluate their potential applicability as slab, rib, micro-resonator or heterostructure waveguides for third order nonlinear devices. Physical vapor deposition techniques such as evaporation [8], pulsed-laser deposition [9] or radio-frequency (RF) sputtering [10] have been shown to be suitable approaches for the fabrication of amorphous chalcogenide thin films of desired optical quality. Specifically, RF co-sputtering is a deposition technique convenient for the studies of compositional dependencies of various physical and chemical characteristics of chalcogenide thin films such as optical properties, structural properties, photosensitivity, phasechange kinetics, solar cells efficiency etc. [11-17]. Several two-band models have been proposed in order to theoretically predict the Kerr coefficient $n_{2}$ and 2PA coefficient $\beta$ for semiconducting materials [18-20]. None of these however, takes into account the localized states in the gap of non-crystalline solids [21]. However, it has been already shown by several authors that the Sheik-Bahae's model, originally developed for direct-gap crystalline semiconductors, may serve as a rough approximation for the estimation of $n_{2}$ and $\beta$ for non-crystalline chalcogenides [7, 22, 23]. In present work, potential use of amorphous chalcogenide films from ternary Ge-Sb-Se system in the field of nonlinear optics is discussed. The thin films were prepared by co-sputtering from 
$\mathrm{GeSe}_{4}$ glass-ceramics and $\mathrm{Sb}_{2} \mathrm{Se}_{3}$ polycrystalline targets. The $\mathrm{GeSe}_{4}$ target was selected based on the promising results for the limitation of optical losses in the mid-IR [24], for the presence of Se-Se bonds with their lone electron pair contributing to large nonlinearities $[25,26]$ and that of $\mathrm{Sb}_{2} \mathrm{Se}_{3}$ for its ability to enhance the NL coefficient of Ge-Se system $[19,27]$. The suitability of these materials for NL applications is predicted based on $n_{2}$ and $\beta$ calculations considering the figure of merit. Furthermore, nearbandgap light irradiation study may provide a valuable information about the photo-stability of fabricated films and hence their potential ability to be used for nonlinear optical applications in the near infrared domain.

Amorphous Ge-Sb-Se thin films were co-sputtered using two targets: $\mathrm{GeSe}_{4}$ target prepared by conventional melt-quenching technique and commercial polycrystalline $\mathrm{Sb}_{2} \mathrm{Se}_{3}$ target (American Elements Corp., Los Angeles, CA, USA). Conditions of the deposition process can be found elsewhere [11]. Thin films were deposited onto two different substrates, specifically borosilicate glass (Schott, BK7) for spectroscopic measurements and photosensitivity and single crystalline silicon (100) for determination of composition and morphology facilitating the flow of charges for EDS-SEM and surface topography. Surface topography measurements were carried out using amplitude-modulated atomic force microscope (AM-AFM, Solver Next, NT-MDT Co., Moscow, Russia) with scanned area of $5 \times 5 \mu \mathrm{m}^{2}$. Chemical composition of co-sputtered films was determined by energy-dispersive X-ray spectroscopy joined with scanning electron microscope (EDS, JSM 6400OXFORD Link INCA, JEOL Ltd., Tokyo, Japan). Optical bandgap energy $\left(E_{g}^{C L}\right)$ and linear refractive index dispersion of prepared thin films were determined from spectroscopic ellipsometry (VASE, J. A. Woollam Co., Inc., Lincoln, NE, USA) data using CodyLorentz oscillator model [28]. Working range of the ellipsometer was 300-2300 nm. Optical bandgap energy and refractive index dispersion curves were used for the estimation of nonlinear optical properties of co-sputtered films. Moreover, thin films were exposed by near-bandgap light for 180 minutes in order to examine the optical response of optical bandgap energy $\left(\Delta E_{g}^{C L}\right)$ and refractive index $\left(\Delta n_{0}\right)$. Irradiation wavelength $\left(\lambda_{i r r}\right)$ was chosen with respect to the penetration depth. In order to prevent the surface of films from photo-enhanced oxidation, samples are placed in the cell filled with pure argon [11]. Ge-Sb-Se films cosputtered from $\mathrm{GeSe}_{4}$ and $\mathrm{Sb}_{2} \mathrm{Se}_{3}$ targets applying various electrical power ratio were found to be of a good optical quality. Optical bandgap energy of co-sputtered films covers the range between the two extreme values of single-cathode depositions of individual targets (sputtered), specifically 1.97 and $1.35 \mathrm{eV}$ for $\mathrm{GeSe}_{4}$ and $\mathrm{Sb}_{2} \mathrm{Se}_{3}$, respectively. Corresponding refractive index at $1.55 \mu \mathrm{m}$ (no) for these two films is 2.44 and 3.33 (Fig. 1a, 1b, Table 1). Moreover, the AFM scans confirmed a good quality of the surface. As shown in the Fig. 1c, RMS roughness of prepared films decreases with increasing antimony content, i.e. with higher electrical power applied on $\mathrm{Sb}_{2} \mathrm{Se}_{3}$ target. While the surface of sputtered $\mathrm{GeSe}_{4}$ film has a grainy surface even if it is amorphous, shifting the composition of the $\mathrm{GeSe}_{4}-\mathrm{Sb}_{2} \mathrm{Se}_{3}$ pseudo-binary towards $\mathrm{Sb}_{2} \mathrm{Se}_{3}$ seems to monotonically reduce the grains by means of both size and amount resulting in low RMS roughness values. Thin films rich in selenium were found repeatedly to undergo slight photodarkening (PD) when irradiated by nearbandgap light, which is represented by negative values of $\Delta E_{g}^{C L}$ (table 1). Although the measurement uncertainty is important, the trends are significant and reproducible. The magnitude of PD becomes smaller when the antimony content exceeds $\sim 25$ at. \%. However, this may be caused by the decrease in selenium content as evidenced by the coefficient $\mathrm{R}$ tending towards the value corresponding to the stoichiometry $\mathrm{R}=1$ for stoichiometric composition) observed during the shift of the composition of the

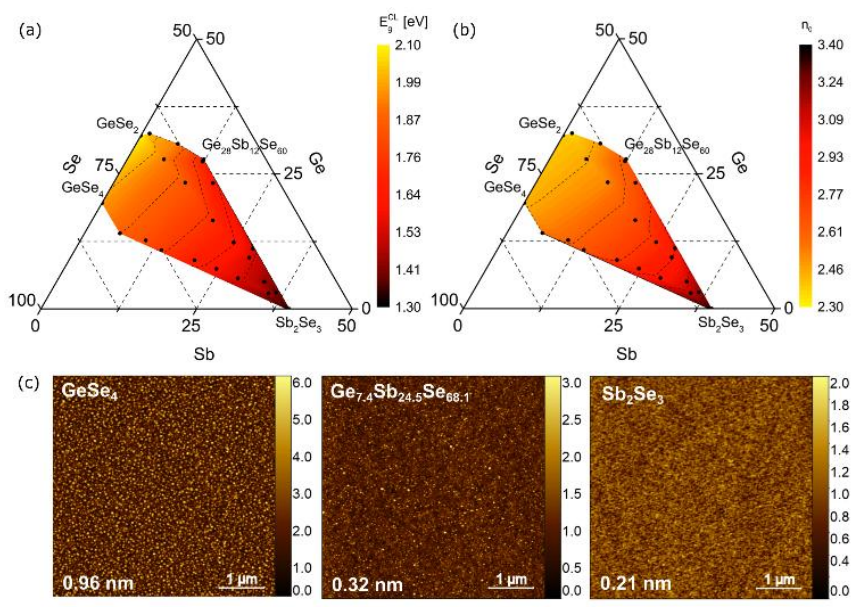

$\mathrm{GeSe}_{4}-\mathrm{Sb}_{2} \mathrm{Se}_{3}$ pseudo-binary towards that of $\mathrm{Sb}_{2} \mathrm{Se}_{3}$.

Fig. 1 (a) Ternary contour diagrams showing the variation of optical bandgap energy and (b) refractive index at $1.55 \mu \mathrm{m}$ for the GeSb-Se co-sputtered thin films - plotted data from table 1 and previous

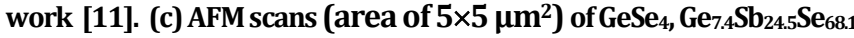
and $\mathrm{Sb}_{2} \mathrm{Se}_{3}$ with RMS roughness values; values of $\mathrm{z}$ axis are in nanometers.

Irradiation wavelengths together with the magnitude of changes in optical energy bandgap and refractive index for selected samples are listed in table 1 . Only small changes if any in refractive index at the level of the uncertainty of refractive index determination from ellipsometric measurements (i.e. \pm 0.01 ) were observed for $\mathrm{Sb}_{39} \mathrm{Se}_{61}$ and $\mathrm{Ge}_{7} \mathrm{Sb}_{25} \mathrm{Se}_{68}$ samples (Table 1). The attenuation of the photosensitivity with an increasing Sb content in ternary Ge-Sb-Se thin films has been reported within several publications $[11,29]$.

Table 1 Summary of co-sputtered films with composition $( \pm 1$ at. \%) and chemical threshold $R$, thickness $I$ ( $\pm 2 \mathrm{~nm})$, optical bandgap energy $E_{g}^{C L}( \pm 0.02 \mathrm{eV})$, refractive index at $1.55 \mu \mathrm{m}$ $n_{0}( \pm 0.01)$, irradiation wavelength $\lambda_{\text {irr }}(\mathrm{nm})$ and irreversible photoinduced changes in optical bandgap energy $\Delta E_{g}^{C L}( \pm$ $0.02 \mathrm{eV})$ and refractive index $\Delta n_{0}( \pm 0.02)$.

\begin{tabular}{ccccccc}
\hline \multicolumn{2}{c}{$\begin{array}{c}\text { Composition } \\
\text { (at. \%) }\end{array}$} & $\mathrm{l}$ & \multicolumn{1}{c}{$\boldsymbol{E}_{\boldsymbol{g}}^{\boldsymbol{C L}}$} & \multicolumn{3}{c}{$\lambda_{\text {irr }}$} \\
$(\mathrm{nm})$ & $(\mathrm{eV})$ & $\mathrm{n}_{0}$ & \multicolumn{2}{c}{$\Delta \boldsymbol{E}_{\boldsymbol{g}}^{\boldsymbol{C L}} \mid \Delta \mathrm{n}_{0}$} \\
\hline $\mathrm{Ge}_{20} \mathrm{Se}_{80} \mid 2.05$ & 710 & 1.97 & 2.44 & 593.5 & $-0.02 \mid 0.01$ \\
$\mathrm{Ge}_{14} \mathrm{Sb}_{6} \mathrm{Se}_{80} \mid 2.20$ & 740 & 1.87 & 2.56 & 635 & $-0.05 \mid-0.01$ \\
$\mathrm{Ge}_{13} \mathrm{Sb}_{10} \mathrm{Se}_{77} \mid 1.87$ & 690 & 1.82 & 2.59 & 635 & $-0.04 \mid 0.00$ \\
$\mathrm{Ge}_{11} \mathrm{Sb}_{14} \mathrm{Se}_{75} \mid 1.76$ & 650 & 1.77 & 2.66 & 656 & $-0.01 \mid-0.01$ \\
$\mathrm{Ge}_{9} \mathrm{Sb}_{20} \mathrm{Se}_{71} \mid 1.47$ & 690 & 1.68 & 2.76 & 730 & $-0.01 \mid 0.01$ \\
$\mathrm{Ge}_{7} \mathrm{Sb}_{25} \mathrm{Se}_{68} \mid 1.32$ & 820 & 1.61 & 2.86 & 730 & $-0.04 \mid 0.02$ \\
$\mathrm{Ge}_{6} \mathrm{Sb}_{29} \mathrm{Se}_{65} \mid 1.20$ & 720 & 1.55 & 2.95 & 730 & $0.00 \mid 0.00$ \\
\hline
\end{tabular}




\begin{tabular}{rlllll}
$\mathrm{Ge}_{3} \mathrm{Sb}_{35} \mathrm{Se}_{62} \mid 1.06$ & 720 & 1.47 & 3.12 & 785 & $0.01 \mid 0.00$ \\
$\mathrm{Sb}_{39} \mathrm{Se}_{61} \mid 1.06$ & 680 & 1.35 & 3.33 & 808 & $0.01 \mid 0.02$ \\
\hline
\end{tabular}

Kumar et al. [30] reported the crossover from PD to photobleaching $(\mathrm{PB})$ when the composition changes from Gedeficient to Ge-rich $\mathrm{Ge}_{X} \mathrm{Se}_{100-\mathrm{x}}$ evaporated films. In their work, the PD in Se-rich GexSe 100-x films induced by monochromatic source $\left(\lambda_{\mathrm{in}}=532 \mathrm{~nm}\right)$ with the beam power density of $500 \mathrm{~mW} \cdot \mathrm{cm}^{-2}$ is considered to be coming from photo-enhanced crystallization of amorphous selenium in Ge-Se matrix as concluded from Raman measurements [30]. In contrast, Zhang et al. have found PB effect even in Ge-deficient sputtered $\mathrm{Ge}_{16.8} \mathrm{Se}_{832}$ when irradiated by 655 $\mathrm{nm}$ laser source at various beam power densities [31]. Lin et al. have suggested that the PD in Ge-Sb-Se co-sputtered films (employing $\mathrm{GeSe}_{2}$ and $\mathrm{Sb}$ targets, respectively) induced by $\lambda_{\mathrm{irr}}=655$ $\mathrm{nm}$ with I=200 mW.cm-2 is caused by Sb-Sb and Ge-Ge homopolar bonds' formation during the irradiation while $\mathrm{PB}$ is the result of homopolar bonds' decomposition with a simultaneous formation of new edge-sharing [GeSe $e_{4 / 2}$ tetrahedra [14]. Therefore, both structural-dependence and the compositional one should be probably taken in account to explain the observation of a PD films in the case of a Se over-stoichiometry and a reduced antimony concentration of our co-sputtered films. Selenium chains seems to have a significant influence on the PD occurrence. The band-gap energy variations are tenuous and Raman spectroscopy was recorded in these films and does not seem to be able to respond significantly to these structural modifications which are probably very weak and potentially essentially related to a conformational change in the Se chains or dimers impacting the electronic structure of the amorphous matrix.

The Kerr coefficient $n_{2}$ and 2PA coefficient $\beta$ at the $1.55 \mu \mathrm{m}$ telecommunication wavelength were estimated by Sheik-Bahae's formalism originally developed for direct-gap crystalline semiconductors [20]. Because the studied films are considered as indirect-gap amorphous semiconductors, Sheik-Bahae's formalism should be taken only for a rough approximation. Nevertheless, the estimated uncertainty of such calculations is at least $15 \%$ of $n_{2}$ and $\beta$ considering the uncertainty of ellipsometric measurements and data fitting and related to the deviation from the measured experimental values. Estimated values of $n_{2}$ and $\beta$ for Ge-Sb-Se cosputtered films depending on the optical bandgap energy are plotted in fig. 2a and 3a, respectively. Values of $n_{2}$ and $\beta$ for $\mathrm{GeSe}_{4}$, $\mathrm{Sb}_{2} \mathrm{Se}_{3}, \mathrm{As}_{2} \mathrm{Se}_{3}$ sputtered thin films deposited at the same conditions from single cathodes are also presented in those figures; with $E_{g}$ of $1.70 \pm 0.02 \mathrm{eV}$ values of $n_{2}$ and $\beta$ were calculated for co-sputtered Ge-Sb-Se films and sputtered $\mathrm{GeSe}_{2}$ thin film elaborated in previous work [11]. The highest nonlinearity by means of Kerr coefficient was found in thin film with composition $\mathrm{Ge}_{3} \mathrm{Sb}_{35} \mathrm{Se}_{62}$ having value of $n_{2}$ of $2.1 \times 10^{-17} \mathrm{~m}^{2} \mathrm{~W}^{-1}$. The lowest $n_{2}$ of $4.9 \times 10^{-18} \mathrm{~m}^{2} \mathrm{~W}^{-1}$ was estimated for sputtered $\mathrm{GeSe}_{4}$ thin film. The shape of the curve in fig. 2a clearly reproduces the shape of the dispersion function $G_{2}$ given by eq. 6 in reference [20]. Estimated values of $n_{2}$ depending on $n_{0}$ are compared to available references as depicted in fig. $2 \mathrm{~b}$. First, Wang et al. measured nonlinear optical properties at $1.55 \mu \mathrm{m}$ of various bulk glasses including Ge-Sb-Se ternary system using z-scan technique [7]. Moreover, Olivier et al. determined values of $n_{2}$ and $\beta$ of bulk glasses from $\left(\mathrm{GeSe}_{2}\right)_{100-\mathrm{x}}\left(\mathrm{Sb}_{2} \mathrm{Se}_{3}\right)_{\mathrm{x}}(\mathrm{x}=5,10,20,30,40$ and 50$)$ system at $1.55 \mu \mathrm{m}$ using beam self-trapping technique [27]. Calculated values of Kerr coefficient in the present work are in a very good agreement with values of $n_{2}$ reported in mentioned two references. The data from work of Tichý and Tichá calculated by generalized Miller rule using Wemple-DiDomenico single oscillator model are not in perfect agreement with values of $n_{2}$ considering the fact that these values represent the Kerr coefficient at the infinite wavelength $(\lambda \rightarrow \infty)$, [32]. Values of $n_{2}$ are also in a good agreement with experimental values obtained by Kuriakose in Ge-Sb-Se chalcogenide slab waveguides using beam self-trapping technique [33]. Noteworthy, good accordance with semi-empirical Miller's rule was found for
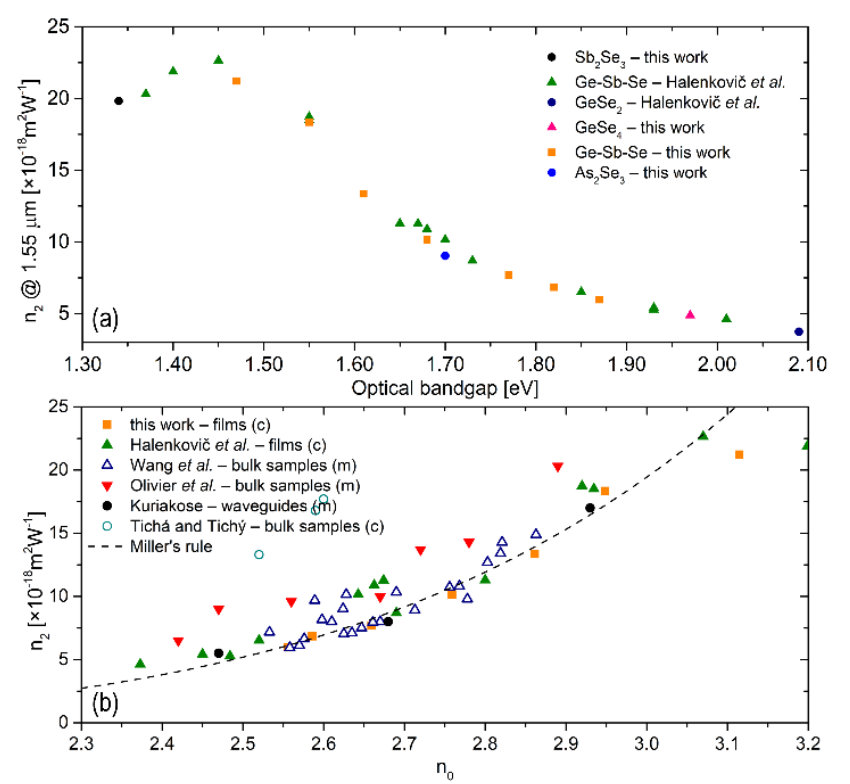

values of Kerr coefficient.

Fig. 2 (a) Dependence of $n_{2}$ at $1.55 \mu \mathrm{m}$ on $E_{g}^{C L}$ of co-sputtered Ge-Sb-Se thin films (this work and reference [11]) and sputtered $\mathrm{Sb}_{2} \mathrm{Se}_{3}$, $\mathrm{GeSe}_{2}$, $\mathrm{GeSe}_{4}$ and $\mathrm{As}_{2} \mathrm{Se}_{3}$ thin films; values of $n_{2}$ obtained by Sheik-Bahae's formalism using $n_{0}(\lambda)$ and $E_{g}^{C L}$ determined by ellipsometry. (b) Comparison of $n_{2}$ depending on $n_{0}$ of Ge-Sb-Se co-sputtered thin films calculated using Sheik-Bahae's formalism at $1.55 \mu \mathrm{m}$ with references: Halenkovič et al. (Sheik-Bahae's formalism for co-sputtered GeSe $2^{-}$ $\mathrm{Sb}_{2} \mathrm{Se}_{3}$ films) [11], Wang et al. (z-scan measurements of bulk glasses of $\sim 2 \mathrm{~mm}$ thickness) [7], Olivier et al. (beam self-trapping technique measurements of bulk glasses of $\sim 2 \mathbf{~ m m}$ thickness) [27], theoretical values of $\boldsymbol{n}_{2}$ (generalized Miller rule by Tichá and Tichý for Ge-Sb-Se bulk glasses) at $\lambda \rightarrow \infty$ [32], Kuriakose (beam self-trapping technique measurements of Ge-Sb-Se waveguides) [33] and semi-empirical Miller rule (dashed curve); $\boldsymbol{c}$ and $\boldsymbol{m}$ in brackets stand for calculated and measured data at $1.55 \mu \mathrm{m}$, respectively.

Figure of merit $(F O M)$ is considered as an expression of a performance of nonlinear device at a specific wavelength $\lambda$. Due to the presence of Heaviside step function in the dispersion function $F_{2}$ within Sheik-Bahae's formalism [20], $\beta$ equals to zero at energies less than half of the bandgap (fig. 3a). In other words, considering the telecommunication wavelength of $1.55 \mu \mathrm{m}(0.8$ $\mathrm{eV})$ as desired wavelength, the optical bandgap energy of the material $\geq 1.60 \mathrm{eV}$ leads to the $\beta=0$ and the FOM according $F O M=n_{2} / \lambda \beta$ cannot be obtained. However, amorphous chalcogenides are generally considered as non-direct gap semiconductors and the 2PA may be expected to be nonzero even 
at the energies below $\mathrm{E}_{\mathrm{g}} / 2$. Moreover, values of $\beta$ depend on both, the measurement technique and the optical bandgap energy $[7,27$, 34]. In order to evaluate the FOM for thin films having $E_{g}^{C L} \geq 1.60 \mathrm{eV}$ in the present work, the value of $\beta$ was set to $1 \times 10^{-11} \mathrm{~m} \cdot \mathrm{W}^{-1}$ for all these films. This assumption is based on reference [27] data where $\beta$ at $1.55 \mu \mathrm{m}$ determined by beam self-trapping technique did not exceed this value in $\left(\mathrm{GeSe}_{2}\right)_{100-\mathrm{x}}\left(\mathrm{Sb}_{2} \mathrm{Se}_{3}\right)_{\mathrm{x}}$ bulk glasses. FOM of all the co-sputtered films including those from the reference [11] depending on linear refractive index $n_{0}$ at $1.55 \mu \mathrm{m}$ is plotted in the fig. $3 \mathrm{~b}$. According to these results, the highest FOM in co-sputtered $\mathrm{GeSe}_{4}-\mathrm{Sb}_{2} \mathrm{Se}_{3}$ is found within the films with the composition $\mathrm{Ge}_{7} \mathrm{Sb}_{25} \mathrm{Se}_{68} \quad(F O M=0.86)$ and $\mathrm{Ge}_{9} \mathrm{Sb}_{20} \mathrm{Se}_{71} \quad(F O M=0.65)$. Corresponding $\mathrm{n}_{2}$ values for these two films are 1.34 and $1.01 \times 10^{-}$ ${ }^{17} \mathrm{~m}^{2} \mathrm{~W}^{-1}$ respectively. We note that the FOM of sputtered $\mathrm{As}_{2} \mathrm{Se}_{3}$ thin films was found to be 0.58 at $1.55 \mu \mathrm{m}$. For comparison with compositions close to those presented in this Letter, Olivier et al. obtained FOM of 1.60 at the same wavelength in the bulk glass of $\mathrm{Ge}_{12.5} \mathrm{Sb}_{25} \mathrm{Se}_{62.5}$. This glass was found to have $n_{2}$ of $2.03 \pm 0.3 \times 10^{-17}$
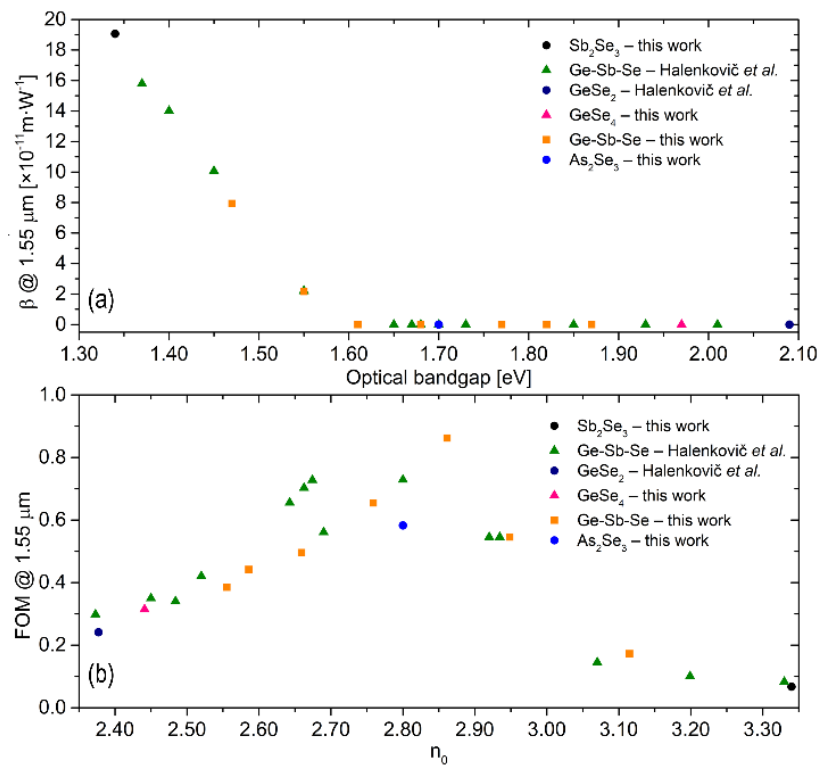

$\mathrm{m}^{2} \mathrm{~W}^{-1}$ according to beam self-trapping measurements $\left(n_{0}=2.89\right.$, $E_{g}^{C L}=1.70 \mathrm{eV}$ ) [27]. It should be noted that co-sputtered films of GeSb-Se possess lower $E_{g}^{C L}$ with respect to bulk glasses in the reference above. Moreover, Wang et al. obtained much larger values of $F O M(>52)$ for $\mathrm{Ge}_{15} \mathrm{Sb}_{10} \mathrm{Se}_{75}\left(E_{g}^{\text {Tauc }}=1.72 \mathrm{eV}\right)$. However, 2PA coefficient $\beta$ in their work was found to be $<0.01 \times 10^{-11} \mathrm{~m} \cdot \mathrm{W}^{-1}$ according z-scan measurements enlarging the value of FOM [7].

Fig. 3 (a) Dependence of $\beta$ at $1.55 \mu \mathrm{m}$ on $E_{g}^{C L}$ of Ge-Sb-Se thin films. (b) Dependence of FOM at $1.55 \mu \mathrm{m}$ on the linear refractive index. Both panels contain calculated data for Ge-Sb-Se co-sputtered films from this work and from reference [11] and sputtered $\mathrm{Sb}_{2} \mathrm{Se}_{3}, \mathrm{GeSe}_{2}, \mathrm{GeSe}_{4}$ and $\mathrm{As}_{2} \mathrm{Se}_{3}$ thin films; values of $\beta$ were obtained by Sheik-Bahae's formalism using $n_{0}(\lambda)$ and $E_{g}^{C L}$ determined by ellipsometry .

Due to the attenuated photosensitivity in combination with large optical nonlinearities, Ge-Sb-Se thin films from $\mathrm{GeSe}_{4}-\mathrm{Sb}_{2} \mathrm{Se}_{3}$ pseudo-binary system seem to be a reasonable alternative to widely used $\mathrm{As}_{2} \mathrm{Se}_{3}(F O M=0.58)$ amorphous chalcogenides as well as to previously studied $\mathrm{GeSe}_{2}-\mathrm{Sb}_{2} \mathrm{Se}_{3}$ pseudo-binary system exhibiting lower content of selenium (highest FOM=0.73). Quantitatively by means of figure of merit at $1.55 \mu \mathrm{m}$, thin films with compositions of $\mathrm{Ge}_{7} \mathrm{Sb}_{25} \mathrm{Se}_{68}$ and $\mathrm{Ge}_{9} \mathrm{Sb}_{20} \mathrm{Se}_{71}$ have to be considered for the future nonlinear optical integrated platforms. Nevertheless, caution should be considered with regard to the FOM because of the difficulty in determining an accurate and reliable value $\beta$ for a band gap $\geq 1.60 \mathrm{eV}$. It is therefore necessary to experimentally verify these predictions so that these Ge-Sb-Se films do not exhibit photosensitive effects that are detrimental to the temporal perennial properties of NLOs [27].

Funding. Czech Science Foundation (18-03823S) and ANR French Foundation (LOUISE, ANR-15-CE04-0001-01).

Disclosures. The authors declare no conflicts of interest.

\section{References}

1. R. W. Boyd, "Chapter 4 - The Intensity-Dependent Refractive Index," in Nonlinear Optics (Third Edition), R. W. Boyd, ed. (Academic Press, Burlington, 2008), pp. 207-252.

2. Y. Zhang, J. Schröder, C. Husko, S. Lefrancois, D.-Y. Choi, S. Madden, B. LutherDavies, B.J. Eggleton, J. Opt. Soc. Am. B 31, 780-787 (2014).

3. Y. Zhang, J. Schröder, C. Husko, S. Lefrancois, D.-Y. Choi, S. Madden, B. LutherDavies, B.J. Eggleton, Opt. Express 21, 7926-7933 (2013).

4. T. Kuriakose, E. Baudet, T. Halenkovič, M.M.R. Elsawy, P. Němec, V. Nazabal, G. Renversez, M. Chauvet, Opt. Commun. 403, 352-357 (2017).

5. S. Jakobs, A. Petrov, M. Eich, J.M. Hales, J.W. Perry, S. Marder, V. Nazabal, P.

Němec, in Nonlinear Optics and Applications VI, 2012, 84340P.

6. K. Tanaka, J. Non-Cryst. Solids 338-340, 534-538 (2004).

7. T. Wang, X. Gai, W. Wei, R. Wang, Z. Yang, X. Shen, S. Madden, B. Luther-Davies, Opt. Mater. Express 4, 1011-1022 (2014).

8. K. Tanaka, Y. Imai, and A. Odajima, J. Appl. Phys. 57, 4897-4900 (1985).

9. P. Němec, J. Charrier, M. Cathelinaud, M. Allix, J.L. Adam, S. Zhang, V. Nazabal,, Thin Solid Films 539, 226-232 (2013).

10. K. Tada, N. Tanino, T. Murai, M. Aoki, Thin Solid Films 96, 141-147 (1982).

11. T. Halenkovič, J. Gutwirth, P. Němec, E. Baudet, M. Specht, Y. Gueguen, J.-C. Sangleboeuf, V. Nazabal, J. Am. Ceram. Soc. 101, 2877-2887 (2018).

12. F. Chen, Z. Zhang, Y. Wang, Q. Nie, X. Shen, S. Dai, Infrared Phys. Technol. 69, 32-35 (2015)

13. J.-Y. Cho, D. Kim, Y.-J. Park, T.-Y. Yang, Y.-Y. Lee, Y.-C. Joo, Acta Materialia 94, 143-151 (2015).

14. L. Lin, G. Wang, X. Shen, S. Dai, T. Xu, Q. Nie, Infrared Phys. Technol. 81, 59-63 (2017)

15. T.-J. Park, S.-Y. Choi, and M.-J. Kang, Thin Solid Films 515, 5049-5053 (2007).

16. H. Wang, G. Wang, D. Shi, X. Shen, Y. Lu, Q. Nie, J. Non-Cryst. Solids 453, 108112 (2016)

17. K. Cheng, Y. Huang, J. Liu, M. Xue, Z. Kuang, Z. Lu, S. Wu, Z., J. All. Comp. 684, 237-244 (2016)

18. M. Dinu, IEEE J. Quantum Electron. 39, 1498-1503 (2003).

19. G. Lenz, J. Zimmermann, T. Katsufuji, M.E. Lines, H.Y. Hwang, S. Spalter, R.E. Slusher, S.W. Cheong, J.S. Sanghera, I.D. Aggarwal, Opt. Lett. 25, 254-256 (2000). 20. M. Sheik-Bahae, D. J. Hagan, and E. W. Van Stryland, Phys. Rev. Lett. 65, 96-99 (1990).

21. E. Romanova, Y. Kuzyutkina, V. Shiryaev, N. Abdel-Moneim, D. Furniss, T. Benson, A. Seddon, S. Guizard, J. Non-Cryst. Solids 480, 13-17 (2018).

22. K. Tanaka, J. Phys. Chem. Solids 68, 896-900 (2007).

23. R. Todorov, J. Tasseva, and T. Babeva, in Photonic Crystals, A. Massaro, ed. (IntechOpen, 2012).

24. J. Troles, V. Shiryaev, M. Churbanov, P. Houizot, L. Brilland, F. Desevedavy, F. Charpentier, T. Pain, G. Snopatin, J.L. Adam, Opt. Mater. 32, 212-215 (2009).

25. J.M. Harbold, F.O. Ilday, F.W. Wise, J.S. Sanghera, V.Q. Nguyen, L.B. Shaw, I.D. Aggarwal, Opt. Lett. 27, 119-121 (2002).

26. J. M. Harbold, F. O. Ilday, F. W. Wise, and B. G. Aitken, IEEE Photon. Technol. Lett. 14, 822-824 (2002).

27. M. Olivier, J.C. Tchahame, P. Nemec, M. Chauvet, V. Besse, C. Cassagne, G. Boudebs, G. Renversez, R. Boidin, E. Baudet, V. Nazabal, Opt. Mater. Express 4, 525-540 (2014). 
28. A.S. Ferlauto, G.M. Ferreira, J.M. Pearce, C.R. Wronski, R.W. Collins, X. Deng, G. Ganguly, J. Appl. Phys. 92, 2424-2436 (2002).

29. M. Olivier, P. Němec, G. Boudebs, R. Boidin, C. Focsa, V. Nazabal, Opt. Mater. Express 5, 781-793 (2015).

30. R. R. Kumar, A. R. Barik, E. M. Vinod, M. Bapna, K. S. Sangunni, and K. V. Adarsh, Opt. Lett. 38, 1682-1684 (2013).

31. S. Zhang, Y. Chen, R. Wang, X. Shen, S. Dai, Sci. Rep. 7, 14585-14585 (2017).

32. H. Tichá and L. Tichý, J. Optoelectron. Adv. Mater. 4, 381-386 (2002).

33. T. Kuriakose, "Demonstration of the spatial self-trapping of a plasmonic wave," (Université Bourgogne Franche-Comté, 2018).

34. K.A. Cerqua-Richardson, J.M. McKinley, B. Lawrence, S. Joshi, A. Villeneuve, Opt. Mater. 10, 155-159 (1998). 